\title{
СЕЙСМОСТОЙКОЕ СТРОИТЕЛЬСТВО
}

УДК 69.058:728.48

DOI: $10.35803 / 1694-5298.2019 .4 .628-633$

\author{
Т.Т. Болотов ${ }^{1}$, Т.Б. Бекболотов ${ }^{1}$ \\ ${ }^{1}$ КГУСТА им. Н. Исанова, Бишкек, Кыргызская Республика
}

\author{
T.T. Bolotov ${ }^{1}$ T.B. Bekbolotov ${ }^{1}$ \\ ${ }^{1}$ KSUCTA n. a. N. Isanov, Bishkek, Kyrgyz Republic \\ Bolotov-2@mail.ru, \\ tolobek.bekbolotov.95@mail.ru
}

\section{ОБСЛЕДОВАНИЕ ТЕХНИЧЕСКОГО СОСТОЯНИЯ НЕЖИЛОГО ЗДАНИЯ INSPECTION OF THE TECHNICAL CONDITION OF A NON-RESIDENTIAL BUILDING}

Бул макалада Сары-Булак айылындагы турак-жай эмес имараттын изилдөөсү камтылган. Изилдөөнүчу объектини толук көруп текшерүү, имараттын негизги курулуш конструкцияларын техникальк абалын баалоо, бузулуу жсана дефектердин пайда болуш себептерин анализдөө, техникалык абалынын категориясын алдын ала орнотуу менен жүргүзүлөт. Изилдөө долбоорлору менен колдонмолор, жоболору иштелип чыккан, кайра калыбына келтирүY же имараттын структураларын күчөтүY боюнча иш-чаралар көрсөтулгөн.

өзөк сөздөр: техникалькк абаль, техникальк абаль категория, текшеруҮ, карап чьггуу, кемчилик, зыян келтирҮҮ, оңдоо, кальбына келтирҮҮ, сактоо.

В данной статье содержится обследование нежилого здания в с. Сарь-Булак. Проведено подробное визуальное обследование объекта исследования, оценка технического состояния основных несущих строительных конструкиий здания, анализ причин возникновения дефектов и повреждений, предварительная установка категории технического состояния. В результате обследования разработаны рекомендации по проектированию, мероприятия по восстановлению или усилению конструкций здания.

Ключевые слова: техническое состояние, категории технического состояния, обследование, визуальное обследование, дефект, повреждение, ремонт, восстановление, эксплуатация.

This article contains a survey of the building in a. Sary-Bulak. A detailed visual examination of the object of study, an assessment of the technical condition of the main loadbearing building structures of the building, an analysis of the causes of defects and damage, and preliminary installation of the technical condition category were carried out. As a result of the survey, design recommendations, measures for the restoration or strengthening of building structures were developed.

Key words: technical condition, categories of technical condition, inspection, visual inspection, defect, damage, repair, restoration, operation.

Оценка технического состояния здания позволяет получить фактическую информацию о текущих функционально-несущих возможностях конструктивных элементов сооружений, их прочности, возможных повреждениях. 
Конструктив практически всех зданий по истечении времени и в результате эксплуатации, простоев недостроенных объектов, климатических, техногенных и иных воздействий, подвергается различного рода повреждениям и деформациям. Подобные конструктивные изменения существенно снижают эксплуатационные возможности сооружений, их долговечность и прочность, в связи с чем оценка технического состояния здания является жизненно важным мероприятием для всех объектов недвижимости. В процессе проведения работ по обследованию была изучена представленная документация и проведено обследование несущих и ограждающих конструкций объекта с проведением необходимых контрольных замеров сечений элементов.

Цель обследования. Обследование одноэтажного здания кафе с магазином, выполнено с целью определения фактического технического состояния несущих и ограждающих конструкций здания в связи с изменением функционального назначения и планируемой реконструкцией. Дать рекомендацию о возможности надстройки дополнительного 2-го этажа и условиях дальнейшей эксплуатации зданий. В соответствии с картой сейсмического районирования территории Кыргызской Республики (приложения “Б”, “В” СНиП КР 20-02:2009 “Сейсмостойкое строительство. Нармы проектирования”) исходный балл ожидаемых землетрясений для с. Сары-булак равен 8 баллам.

Состав и методика проведения работ.

Обследование и оценка сейсмостойкости здания проведена с соблюдением требований следующих действующих норм на момент обследования:

- СНиП 22-01-98 КР “Оценка сейсмостойкости здания существующей застройки”;

- СНиП КР 20-02:2009 “Сейсмостойкое строительство. Нармы проектирования”;

- РДС 31-01-99 "Порядок проведения работ по инженерному обследованию зданий и сооружений , подлежащих перепрофилированию, перепланировке или реконструкции на территории Кыргызской Республики";

- СНиП КР 31-01:2001 “Перепрофилирование помещений жилых зданий существующей застройки";

- ГОСТ 22690-88. Бетоны. Определение прочности механическими методами неразрушающего контроля;

- СНиП 2.03.01-84* “Бетонные и железобетонные конструкции”;

- СНиП 11-22-81 “Каменные и армокаменные конструкции”;

- СНиП “Нагрузки и воздействия”;

- Методические указания по техническому обследоанию эксплуатируемых зданий.

При обследовании произведен визуальный осмотр строительных конструкций здания в непосредственной близости, выборочные вскрытия конструкций и оценка прочности бетона фундамента и перемычек.

Оценка сейсмостойкости здания выполнялась в соответствии с СНиП 22-01-98 “Оценка сейсмостойкости здания существующей застройки”.

Правила обследования и мониторинга технического состояния» [2], в следующей последовательности:

Изучение, имеющейся на момент обследования, проектной и технической документации.

Визуальное и инструментальное обследование конструкций с контрольными замерами, фотографирование узлов, фрагментов и деталей, дефектов, а также проведение необходимых замеров сечений элементов.

Контрольные инструментальные замеры сечений элементов несущих и ограждающих конструкций, а также фотофиксация проводились с помощью следующего лабораторного оборудования: рулетка измерительная ценой деления 1мм, штангенциркулем ЩЦ-ІІІ №34340480; микроскопом МПБ-3, линейка измерительная металлическая фотоаппарат Kodak. Испытание прочности бетона конструкций производилось методом пластических 
деформаций с использованием эталонного молотка Оргтехстроя и в соответствии с требованиями ГОСТ 22690-88.

Предварительное обследование включает визуальной осмотр контрукций и сбор следующих данных: время возведения; конструктивная схема здания; наличие повреждений; проектная и испытательная документация; информацияоб изменениях конструктивной схемы несущих конструкций, нагрузок или функционального назначения в процессе строительства.

Анализ проектной документации является обязательным этапоми включает определение соответствия проектных решений требованиям действующих норм - СНиП КР 20-02:2009““Сейсмостойкое строительство. Нармы проектирования”.

В результате обследования получают следующие данные, необходимые для оценки технического состояния: фактическое конструктивное решение здания; прочностные характеристики бетона конструкций; расположение и сечение арматуры конструкций; характер расположения и ширину раскрытия трещин; эскизы выборочных вскрытий с указанием класса и диаметра арматуры в данных сечениях.

В результате выполненных работ должно быть представлено техническое заключение о состоянии конструкций рассматриваемого здания с рекомендациями по дальнейшей эксплуатации. Здание построено в 80 -х годах прошлого столетия.

По данным техпаспорта здание перепрофилировано под кафе с магазином в 2004 году. Позднее дополнительно к зданию пристроено помещение из глиняного кирпича-сырца. Помещение пристроено с северной уличной стороны здания.

Обследованное здание одноэтажное, с подвалом, прямоугольной формы в плане с наружными размерами основной части 1-го этажа 9,3х16,4 м. Размеры подвала в продольном направлении предусмотрены больше размеров 1-го этажа и составляют 28,0x9,3 м. Размеры возведенной из кирпича-сырца пристройки на 1 -м этаже 9,3х6,2м (Рис.1).

Конструктивная схема здания решена с несущими поперечными кирпичными стенами, с двумя продольными наружными самонесущими кирпичными стенами и перекрытием из сборных железобетонных панелей с круглыми пустотами заводского изготовления. Пространственная жесткость здания обеспечивается совместной работой армированной кладки стен с жестким диском перекрытия.

Высота помещений 1-го этажа составила - 2,85 м (от поверхности пола до потолка), подвала - 2,80 м.

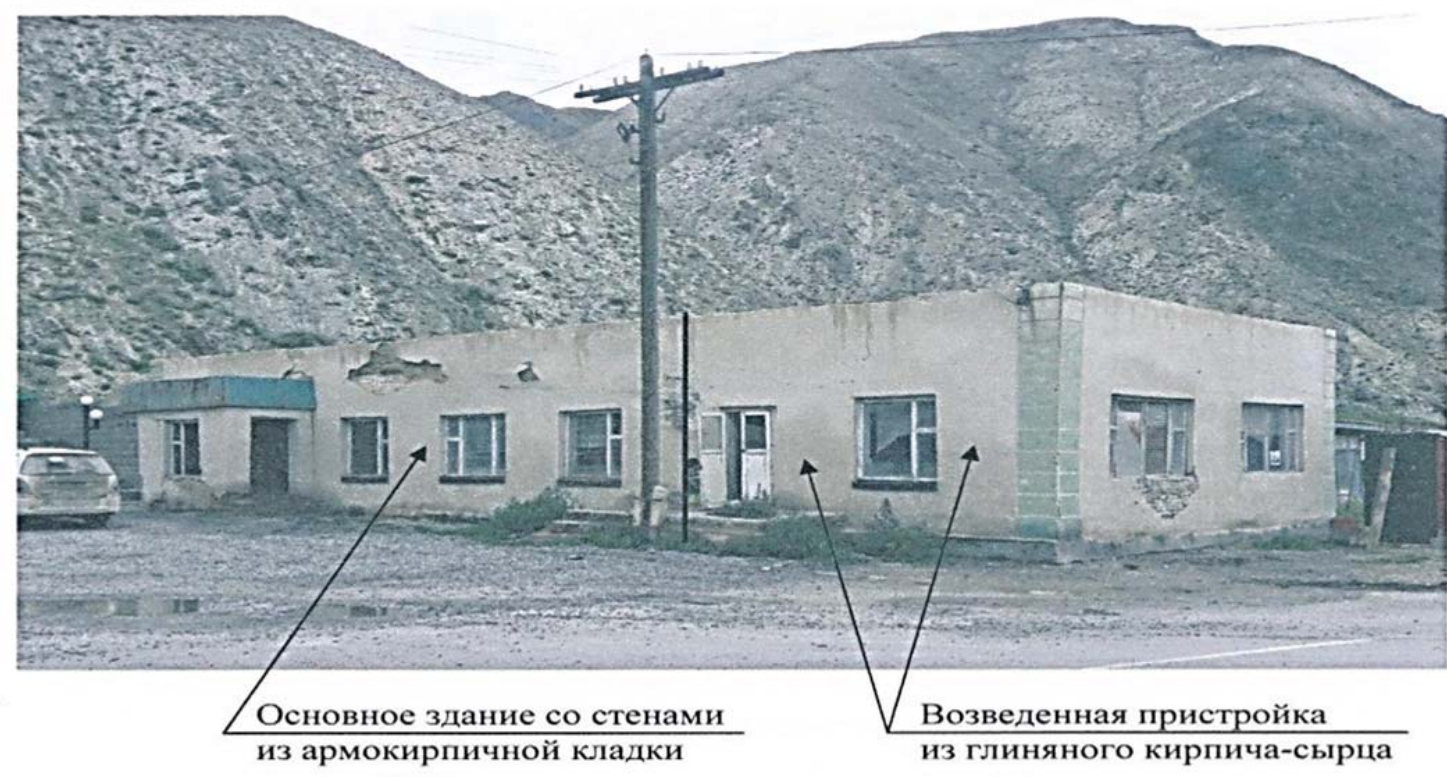

Рис.1. Общий вид обследованного здания 
Фундаменты под стенами - монолитные ленточные бетонные толщиной 400мм. Прочность бетона в пределах кл. В10 - В 12,5.

Стены наружные и внутренние несущие поперечные кирпичные толщиной 380мм. Шаг поперечных несущих стен, на которые опираются плиты перекрытия 6,0 и 3,6 м. Расстояние между продольными самонесущими стенами 8,8 м в осях.

Стены подвала монолитные бетонные кл. В10-В 12,5.

Плиты перекрытия - сборные железобетонные многопустотные панели заводского изготовления. Толщина плит 220мм, ширина 1190мм, в уровне перекрытия предусмотрена антисейсмическая обвязка. Местами имеются монолитные железобетонные участки перекрытия. Сборные плиты перекрытия над 1-м этажом уложены на стены под уклоном в целях создания ската мягкой рулонной кровли.

Перемычки над проемами - железобетонные из бетона кл. В15.

Перегородки помещений армокирпичные толщиной 120мм и из глиняного кирпичасырца выполненные при перепланировке.

Между подвалом и 1-м этажом предусмотрена межэтажная внутренняя лестница.

Косоуры лестницы выполнены из стальных прокатных швеллеров №18 ( $\mathrm{b}=180 \mathrm{~mm})$. Ступени и площадки железобетонные класса В15.

Поль в помещениях цементно-песчаная стяжка по бетонной подготовке.

Кровля здания мягкая рулонная двухскатная. Парапеты выполнены из глиняного кирпича сырца.

Конструктивная схема здания по степени уязвимости к сейсмическим воздействиям согласно СНиП 22-01-98 КР «Оценка сейсмостойкости зданий существующей застройки» относится к подгруппе 1.3 (Здания с несущими кирпичными стенами и с железобетонными перекрытиями, построенные после 1957 г.) и при 8 баллах сейсмичности площадки строительства является уязвимой.

Пристройка с уличной стороны здания возведена поверх существующих бетонных стен и сборного перекрытия подвала здания. Наружные размеры пристройки в плане 9,3х6,2м. Пристроенная и основная части здания приведены на схеме плана 1-го этажа в приложении.

Cтены возведенной пристройки выполнены из глиняного кирпича - сырца.

Перекрытие по деревянным балкам. Потолки оштукатурены по дранке.

Перемычки над проемами из деревянных досок.

Конструкции рассматриваемой пристройки из кирпича-сырца не отвечают современным требованиям действующих норм и правил по сейсмостойкому строительству СНиП КР 20-02:2009 "Сейсмостойкое строительство. Нормы проектирования" и являются не сейсмостойкими.

Конструктивная схема пристройки по степени уязвимости к сейсмическим воздействиям согласно СНиП 22-01-98 КР «Оценка сейсмостойкости зданий существующей застройки» относится к подгруппе 9.5 и при сейсмичности площадки строительства 8 баллов является сильно уязвимой.

Инженерные сети.

Обследуемое здание оборудовано инженерными сетями, включая электроснабжение, водоснабжение и отопление.

При обследовании произведен визуальный осмотр конструкций здания в непосредственной близости, вскрытия местами конструкций, оценка прочности бетона фундамента, перемычек и поперечных рам.

По результатам проведенных испытаний прочность бетона фундамента составила в пределах марки 100-150, что соответствует классу В10-В 12,5.

Техническое состояние фундаментов на момент обследования классифицируется как работоспособное. 
Для дальнейшей сохранности здания и предотвращения дальнейшего проникновения атмосферной влаги к фундаментам и грунтам основания, рекомендуется выполнить работы по восстановлению эксплуатационных показателей грунтов обратной засыпки пазух котлована и отмостки.

При ремонте отмостки, обратную засыпку пазух котлована выполнять с послойным уплотнением грунта до коэффициента уплотнения 0,95 (до плотности скелета грунта не менее 1,65 т/м³) в соответствии с требованиями СНиП 3.02.01-87 «Земляные сооружения, основания и фундаменты»[3]. Для грунтов обратной засыпки использовать суглинок или глину. Новую отмостку по периметру здания необходимо устроить шириной не менее 1,0 м с активным уклоном от здания не менее $5 \%$.

Прочность бетона перемычек и железобетонных рам составила не менее $200 \mathrm{\kappa r} / \mathrm{cm}^{2}$, что соответствует классу бетона по прочности на сжатие не менее В15.

В здании использован керамический кирпич марки по прочности М75, марок по морозостойкости мрз.15.

На сегодняшний день конструкция стен не отвечает современным требованиям по теплозащите, необходимо утепление эффективным минераловатным утеплителем.

Результаты проведенного обследования показали, что техническое состояние конструкций здания в целом удовлетворительное и пригодное для дальнейшей эксплуатации и планируемой реконструкции. Трещин превышающих нормативные требования в несущих конструкциях не зафиксировано.

Однако при обследовании местами были зафиксированы повреждения и дефекты, образовавшиеся при ненадлежащей эксплуатации здания. Зафиксированные повреждения и дефекты следующие:

1. Поверхности кирпичной кладки наружных стен 1-го этажа с южной стороны здания разрушаются из-за длительного воздействия влаги и попеременного замораживания и оттаивания в зимний период. В этих местах необходимо кладку расчистить от разрушенных участков до неповрежденных частей и оштукатурить по металлической сетке раствором марки не ниже М200.

2. Местами нижняя арматурная сетка плит перекрытия обнажена и подвержена поверхностной коррозии вследствие протечек через кровлю. Поврежденные участки плит перекрытия тщательно расчистить и оштукатурить раствором марки не менее М200.

3. Кровля здания разрушена вследствие чего происходят проточки при атмосферных осадках. Необходимо произвести капитальный ремонт кровли и выполнить скатную крышу после планируемой реконструкции.

4. Конструкции возведенной пристройки со стенами из глиняного кирпича-сырца не соответствуют требованиям норм по сейсмостойкому строительству СНиП КР 20-02:2009 “Сейсмостойкое строительство. Нормы проектирования".

В настоящее время планируется реконструкция здания с возведением дополнительного 2-го этажа в облегченных металлических конструкциях.

Результаты проведенного обследования показали, что планируемая реконструкция технически возможна и допускается требованиями норм на основании результатов обследования.

Вывод по строительному техническому обследованию здания. Несущие и ограждающие конструкции надстраиваемого 2-го этажа выполнять в легких металлических конструкциях на каркасной основе. При этом обеспечить связь несущих конструкций (стоек) надстраиваемого этажа с несущими конструкциями существующего здания.

Надстройку планируемого 2-го этажа возводить в пределах несущих кирпичных стен основной части здания. Возведение настройки над пристройкой из кирпича-сырца не допускается.

В надстраиваемом этаже не должны предусматриваться складские и тому подобные помещения, в которых возможно образование значительных нагрузок. Так как сборные 
плиты перекрытия над 1-м этажом уложены с уклоном то выравнивание основания пола планируемого 2-го этажа выполнять облегченными каркасными деревянными или металлическими конструкциями. Использование для выравнивания основания пола тяжелых сыпучих или тяжелых растворов не допускается.

Разрушенные места кирпичной кладки наружных стен из-за длительного воздействия влаги и попеременного замораживания и оттаивания в зимний период необходимо расчистить до неповрежденных частей и усилить сеткой сварной $04 \mathrm{Bp}-1$ с ячейкой 100x100мм в слое раствора марки не ниже М200. Толщину слоя усиления принять не менее 40MM.

Поврежденные участки плит перекрытия вследствие протечек через кровлю тщательно расчистить и оштукатурить раствором марки не менее М100.

В целях повышения несущей способности при сейсмических воздействиях внутренние несущие поперечные кирпичные стены подвала и 1-го этажа усилить сеткой сварной 04 Вр-1 с ячейкой 100x100мм в слое раствора марки не ниже М200. Толщину слоя усиления принять не менее 40мм.

Производство работ по усилению и реконструкции вести с соблюдением требований СНиП КР 12-01-99 «Техника безопасности в строительстве», СНиП 3.03.01-87 «Несущие и ограждающие конструкции».

При проектировании реконструкции должны быть обеспечены требования санитарных норм № 4396-87 и № 1304-75, а также пожарной безопасности, в соответствии с межгосударственными строительными нормами и правилами МСН 2.02-01-97 «Пожарная безопасность зданий и сооружений».

Проектные и строительные работы должны выполняться организациями, имеющими соответствующие лицензии и квалификационно сертифицированных специалистов. В обязательном порядке следует составлять акты промежуточной приемки ответственных конструкций и освидетельствования скрытых работ. Производство работ должно отвечать требованиям правил техники безопасности при проведении ремонтных работ. Следует сводить к минимуму повреждение конструкций и исключить возможность их обрушения.

Обеспечить надлежащий водоотвод поверхностных и талых вод с прилегающих к зданиям участков территории.

\section{Список литературы}

1. Рекомендации по оценке состояния и усилению строительных конструкций промышленных зданий и сооружений НИИСК. [Электронный ресурс] Режим доступа: http://www.gostrf.com/normadata/1/4294845/4294845893.pdf

2. Тетиор А.Н. Обследование и испытание сооружений [Электронный ресурс] / А.Н. Тетиор, В.Н.Померанцев // Учебн. Для ВУЗов. - Режим доступа:

https://elib.pstu.ru/vufind/Record/RUPSTUbooks177381

3. СНиП 3.02.01-87 «Земляные сооружения, основания и фундаменты»

4. Бетоны. Методы определения прочности по образцам, отобранным из конструкций: ГОСТ 28570-90. Введ. 01.01.91. М., 1991.

5. Бутырин А.Ю. Судебная строительно-техническая экспертиза (теоретические, методические и правовые основы) [Текст] /А.Ю.Бутырин. - М.: Изд. Городец, 1998. -196с.

6. Гранев В.В. Вопросы обследования технического состояния зданий и сооружений [Текст] / В.В. Гранев,А.Г. Гидоян // Промышленное и гражданское строительство. - 1999. N 5.

7. Мамасалиева А.А. Техническое состояние трехэтажного здания. [Текст] / А.А.Мамасалиева // Вестник КГУСТА. -2018. - № 3(61). - с.91-95. 